\title{
Optimal hydration volume among high-risk patients with advanced congestive heart failure undergoing coronary angiography
}

\author{
Shi-Qun Chen ${ }^{1,2, *}$, Yong Liu ${ }^{1,3, *}$, Wei Jie Bei ${ }^{1, *}$, Ying Wang ${ }^{3, *}$, Chong-Yang Duan ${ }^{4, *}$, \\ Deng-Xuan Wu ${ }^{1, *}$, Kun Wang ${ }^{1}$, Ping Yan Chen ${ }^{4}$, Ji-Yan Chen ${ }^{1}$, Ning Tan ${ }^{1}$ and Li- \\ Wen Li ${ }^{1}$ \\ ${ }^{1}$ Department of Cardiology, Guangdong Provincial Key Laboratory of Coronary Heart Disease Prevention, Guangdong \\ Cardiovascular Institute, Guangdong General Hospital, Guangdong Academy of Medical Sciences, Guangzhou, Guangdong, \\ China \\ ${ }^{2}$ Department of Cardiology, Guangdong General Hospital Zhuhai Hospital (Zhuhai Golden Bay Center Hospital), Zhuhai, \\ Guangdong, China \\ ${ }^{3}$ The George Institute for Global Health, Sydney, Australia \\ ${ }^{4}$ National Clinical Research Center for Kidney Disease, State Key Laboratory of Organ Failure Research, Department of \\ Biostatistics, School of Public Health and Tropical Medicine Southern Medical University, Guangzhou, Guangdong, China \\ *These authors contributed equally to this work \\ Correspondence to: Li-Wen Li, email: gdghllw@163.com \\ Ning Tan, email: tanning100@126.com \\ Keywords: heart failure; acute kidney injury; hydration; contrast; coronary angiography \\ Received: May 30, $2017 \quad$ Accepted: March 10, $2018 \quad$ Published: May 04, 2018 \\ Copyright: Chen et al. This is an open-access article distributed under the terms of the Creative Commons Attribution License 3.0 \\ (CC BY 3.0), which permits unrestricted use, distribution, and reproduction in any medium, provided the original author and source \\ are credited.
}

\section{ABSTRACT}

We investigated the relationship between weight-adjusted hydration volumes and the risk of developing contrast-induced acute kidney injury (CI-AKI) and worsening heart failure (WHF) and explored the relative safety of optimal hydration volumes in patients with advanced congestive heart failure (CHF) undergoing coronary angiography (CAG) or percutaneous coronary intervention. We included 551 patients with advanced CHF (New York Heart Association class $>2$ or history of pulmonary edema) undergoing CAG (follow-up period $2.62 \pm 0.9$ years). There was a significant association between hydration volume-to-weight ratio (HV/W) (quintile Q1, Q2, Q3, Q4, and Q5) and the incidence of CI-AKI $(3.7 \%, 14.6 \%, 14.3 \%, 21.1 \%$, and $31.5 \%$, respectively) and WHF (3.6\%, 5.4\%, 8.3\%, 13.6\%, and $19.1 \%$, respectively) (all P-trend $<0.001)$. Receiver operating curve analysis indicated that $\mathrm{HV} / \mathrm{W}=15 \mathrm{~mL} / \mathrm{kg}$ and the mean HV/W (60.87\% sensitivity and $64.96 \%$ specificity) were fair discriminators for CI-AKI (C-statistic 0.696). HV/W $>15 \mathrm{~mL} / \mathrm{kg}$ independently predicted CI-AKI (adjusted odds ratio [OR] 2.33; $P=0.016$ ) and WHF (adjusted OR 2.13; $P=0.018$ ). Moreover, both CI-AKI and WHF were independently associated with increased long-term mortality. Thus, for high-risk patients with advanced CHF undergoing CAG, HV/W >15 mL/ kg might be associated with an increased risk of developing CI-AKI and WHF. The potential benefits of a personalized limitation of hydration volume need further evaluation.

\section{INTRODUCTION}

Contrast-induced acute kidney injury (CI-AKI), a common complication following coronary angiography $(\mathrm{CAG})$ or percutaneous coronary intervention (PCI), is associated with in-hospital and long-term mortality, especially among high-risk patients such as those with congestive heart failure (CHF) [1,2]. Adequate hydration is used as a basic and effective strategy for the prevention of CI-AKI among patients undergoing CAG or PCI, 
including patients with advanced CHF (as defined by a New York Heart Association [NYHA] functional classification greater than 2). Furthermore, it has been recommended that the speed of fluid administration be reduced to $0.5 \mathrm{~mL} / \mathrm{kg} / \mathrm{h}$ for patients with heart failure to avoid fluid overload and in-hospital worsening heart failure (WHF), which is associated with poorer short- and long-term outcomes [3]. However, there is no consensus on the optimal hydration volume for the prevention of CIAKI in patients with advanced $\mathrm{CHF}[4,5]$.

Patients with multiple comorbidities (heart, renal, and liver dysfunction) have a higher risk of fluid overload [6]. Fluid overload is an independent risk factor for acute kidney injury and mortality in critically ill patients [7-9]. Although it has been suggested that hydration rates be adjusted by body weight $(\mathrm{mL} / \mathrm{kg} / \mathrm{h})$ [10-12], there is a paucity of studies on the optimal hydration volume for avoiding fluid overload in patients with a high risk of WHF and CI-AKI.

In the present study, we investigated the relationship between weight-adjusted hydration volumes and the risk of developing CI-AKI and WHF and explored the relative safety of optimal hydration volumes in patients with advanced $\mathrm{CHF}$ undergoing $\mathrm{CAG}$ or PCI.

\section{RESULTS}

A total of 551 patients with advanced CHF (27.4\% female; age $66 \pm 11$ years) were included in the final analysis (Supplementary Figure 1). There was a significant association between hydration volume-to-weight ratio (HV/W) (quintile Q1 [<8.1 mL/kg, $n=110]$, Q2 [8.1$10.64 \mathrm{~mL} / \mathrm{kg}, n=111]$, Q3 [10.65-14.75 mL/kg, $n=109]$, Q4 [14.75-20 mL/kg, $n=111]$ and Q5 [> $20 \mathrm{~mL} / \mathrm{kg}, n=$ $110])$ and the incidence of CI-AKI $(3.7 \%, 14.6 \%, 14.3 \%$, $21.1 \%$, and $31.5 \%$, respectively) and WHF (3.6\%, 5.4\%, $8.3 \%, 13.6 \%$, and $19.1 \%$, respectively) (all P-trend $<$ 0.001) (Figure 1). Receiver operating characteristic (ROC) curve analysis showed a correlation between $\mathrm{HV} / \mathrm{W}$ ratio and CI-AKI, with a C-statistic of 0.696. In particular, the analysis showed that at a cut-off level of $>15 \mathrm{~mL} / \mathrm{kg}$ and at the mean value of $\mathrm{HV} / \mathrm{W}$, the $\mathrm{HV} / \mathrm{W}$ ratio exhibited $60.87 \%$ sensitivity and $64.96 \%$ specificity for predicting CI-AKI (Figure 2).

\section{Characteristics of patients with $\mathrm{HV} / \mathrm{W}>15 \mathrm{~mL} /$ $\mathrm{kg}$ and $\mathrm{HV} / \mathrm{W} \leq 15 \mathrm{~mL} / \mathrm{kg}$}

The patients in the $\mathrm{HV} / \mathrm{W}>15 \mathrm{~mL} / \mathrm{kg}$ group were significantly older, had higher log B-type natriuretic peptide (BNP) levels and poorer renal function, were more likely to undergo emergency PCI, had more hypotensive episodes and coronary artery lesions, had higher Mehran risk scores [2], and more frequently required diuretics (Table 1). However, there were no significant inter-group differences with respect to diabetes mellitus, anemia, and contrast volume.

\section{Outcomes among patients with $\mathrm{HV} / \mathrm{W}>15 \mathrm{~mL} /$ $\mathrm{kg}$ and $\mathrm{HV} / \mathrm{W} \leq 15 \mathrm{~mL} / \mathrm{kg}$}

CI-AKI incidence was significantly higher in the $\mathrm{HV} / \mathrm{W}>15 \mathrm{~mL} / \mathrm{kg}$ than in the $\mathrm{HV} / \mathrm{W} \leq 15 \mathrm{~mL} / \mathrm{kg}$ group (26.3\% vs $11.0 \%, P<0.001)$; the same trend was noted for WHF (16.7\% vs 5.7\%, $P<0.001$, Table 2$)$.

The patients in the higher HV/W group showed higher rates of mortality and major adverse clinical events (MACE) than the lower HV/W group (2-year mortality: $24.6 \%$ vs $9.1 \%, P<0.001$; 3-year mortality: $25.1 \%$ vs $10.9 \%, P<0.001$; 2-year MACE: $46.0 \%$ vs $26.5 \%, P$ $<0.001$; 3-year MACE: $51.7 \%$ vs $32.1 \%, P<0.001$ ). However, re-hospitalization rates were similar between the $\mathrm{HV} / \mathrm{W}>15 \mathrm{~mL} / \mathrm{kg}$ and $\mathrm{HV} / \mathrm{W} \leq 15 \mathrm{~mL} / \mathrm{kg}$ groups (2-year re-hospitalization: $21.5 \%$ vs $17.3 \%, P=0.299$; 3 -year rehospitalization: $28.2 \%$ vs $21.2 \%, P=0.108$ ) (Table 2 ).

\section{Logistic regression analysis for association between HV/W ( $>15 \mathrm{~mL} / \mathrm{kg}$ ) and CI-AKI and WHF}

Multivariate logistic regression analysis revealed that compared with $\mathrm{HV} / \mathrm{W} \leq 15 \mathrm{~mL} / \mathrm{kg}, \mathrm{HV} / \mathrm{W}>15 \mathrm{~mL} / \mathrm{kg}$ was an independent predictor of CI-AKI (odds ratio [OR], 2.33; 95\% confidence interval $[\mathrm{CI}], 1.26-4.31 ; P=0.016$; Table 3 ) and WHF (OR, 2.13; 95\% CI, 1.14-3.99; $P=$ 0.018; Table 4).

\section{Long-term mortality according to CI-AKI and WHF}

Long-term mortality was significantly higher in patients with CI-AKI than in patients without CI-AKI (41.4\% vs $11.4 \%, P<0.001)$. Long-term mortality was also higher in patients with WHF than in patients without WHF (45.8\% vs $12.9 \%, P<0.001)$; the same trend was noted for MACE (CI-AKI: $61.6 \%$ vs $35.1 \%, P<0.001$; WHF: $63.2 \%$ vs $37.0 \%, P<0.001$ ) (Supplementary Figure 2). Kaplan-Meier curve analyses revealed that CI-AKI and WHF were significantly associated with an increased risk of mortality (CI-AKI alone: $P<0.001$; WHF alone: $P<0.001$; CI-AKI and WHF: $P<0.001$, (Supplementary Figure 3).

\section{Cox regression analysis of the association between CI-AKI and WHF and long-term mortality}

Multivariate Cox regression analysis revealed that CI-AKI (hazard ratio [HR] 2.52; 95\% CI 1.51-4.21; $P$ $<0.001$ ) and WHF (HR 2.34; 95\% CI 1.36-4.02; $P=$ 
0.002;) were significantly associated with mortality, after adjusting for confounding clinical factors including age, anemia, creatinine clearance, diuretics, and emergency PCI; the same trend was noted for MACE (Figure 3). In addition, the combination of CI-AKI with WHF was also found to increase the risk of mortality (HR 2.92; 95\% CI 1.43-5.94; $P=0.003$ ), after adjusting for confounding clinical factors (Figure 4).

\section{DISCUSSION}

To our knowledge, this is the first study to explore the optimal hydration volume for the prevention of CIAKI after CAG or PCI among patients with advanced CHF. Our data showed that high hydration volumes $(\mathrm{HV} / \mathrm{W}>15 \mathrm{~mL} / \mathrm{kg})$ were significantly associated with an increased risk of CI-AKI and WHF. Moreover, CI-AKI

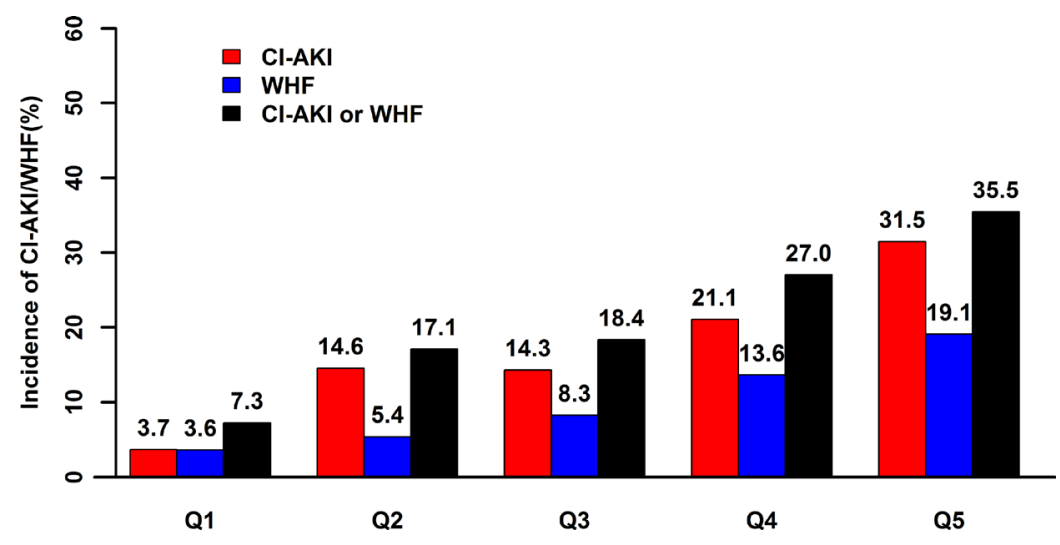

Figure 1: Relationship between HV/W and CI-AKI and WHF. The association between HV/W and the percentage of patients with CI-AKI and/or WHF following CAG was significant (P-trend $<0.001)$. HV/W, hydration volume-to-weight $(\mathrm{mL} / \mathrm{kg}$ ); CI-AKI, contrast-induced acute kidney injury; WHF, worsening heart failure.

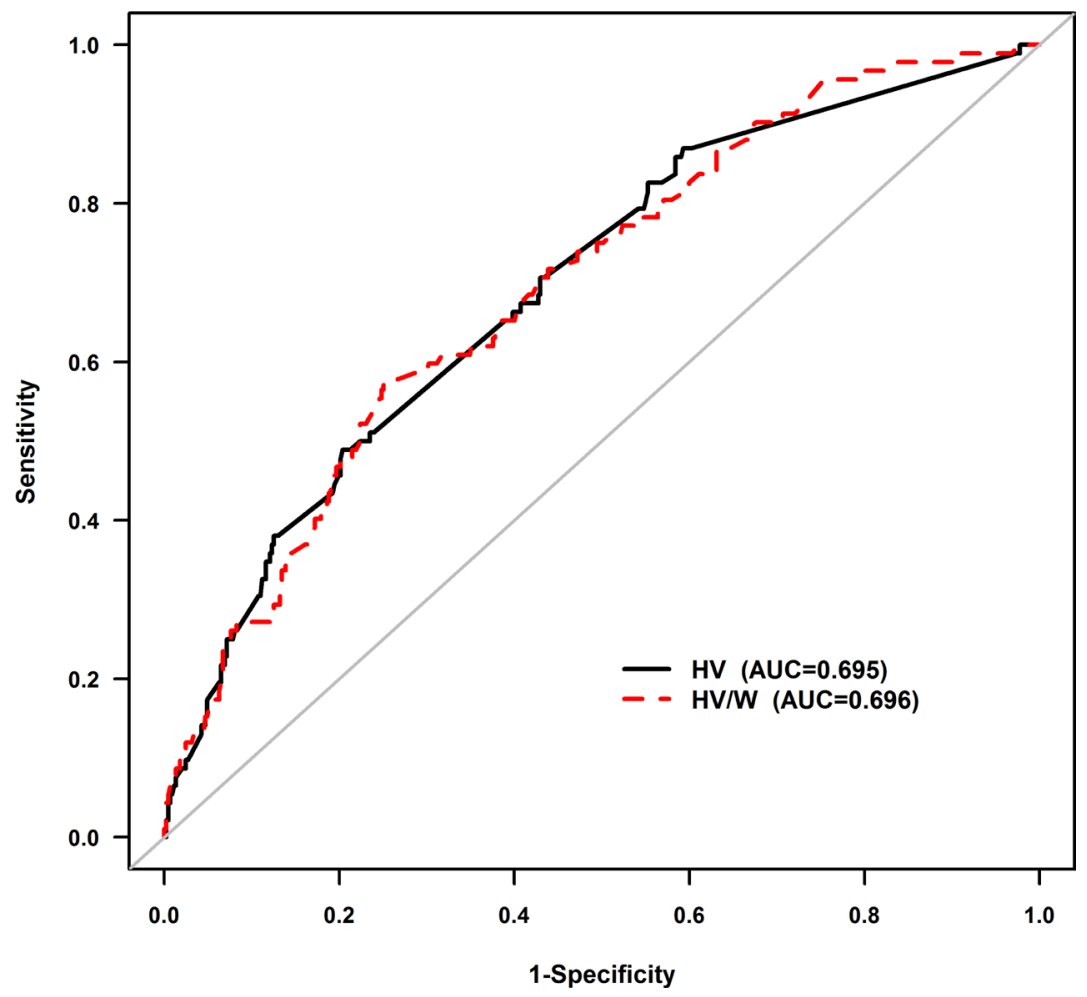

Figure 2: Receiver-operating characteristic curve analysis of the association between HV/W and CI-AKI. At a cut-off value of $>15 \mathrm{~mL} / \mathrm{kg}$, HV/W exhibited $60.87 \%$ sensitivity and $64.96 \%$ specificity for detecting CI-AKI. The C-statistic was 0.696 . HV/W, hydration volume-to-weight (mL/kg); CI-AKI, contrast-induced acute kidney injury. 
Table 1: Baseline patient and procedural characteristics according to the hydration volume-to-body weight ratio $(\mathrm{HV} / \mathrm{W} \leq 15$ and $\mathrm{HV} / \mathrm{W}>15 \mathrm{~mL} / \mathrm{kg})$

\begin{tabular}{|c|c|c|c|c|}
\hline \multirow[b]{2}{*}{ Characteristics } & \multirow[b]{2}{*}{$\begin{array}{c}\text { Total } \\
(n=\mathbf{5 5 1})\end{array}$} & \multicolumn{3}{|c|}{ HV/W } \\
\hline & & $\begin{array}{c}\mathrm{HV} / \mathrm{W} \leq 15 \mathrm{~mL} / \mathrm{kg} \\
(n=334)\end{array}$ & $\begin{array}{c}\mathrm{HV} / \mathrm{W}>15 \mathrm{~mL} / \mathrm{kg} \\
(n=217)\end{array}$ & $P$-value \\
\hline Age, years & $66.42 \pm 10.84$ & $64.68 \pm 10.89$ & $69.09 \pm 10.24$ & $<0.001$ \\
\hline Age > 75 y, n (\%) & $126(22.9)$ & $57(17.1)$ & $69(31.8)$ & $<0.001$ \\
\hline Female sex, n (\%) & $151(27.4)$ & $88(26.3)$ & $63(29.0)$ & 0.490 \\
\hline $\mathrm{CrCl}, \mathrm{mL} / \mathrm{min}$ & $60.84 \pm 27.60$ & $68.71 \pm 26.25$ & $48.73 \pm 25.19$ & $<0.001$ \\
\hline $\mathrm{CrCl} \geq 60 \mathrm{~mL} / \mathrm{min}, n(\%)$ & $249(45.2)$ & $195(58.4)$ & $54(24.9)$ & $<0.001$ \\
\hline Serum creatinine, $\mu \mathrm{mol} / \mathrm{L}$ & $106.21 \pm 49.27$ & $93.98 \pm 38.08$ & $125.03 \pm 57.95$ & $<0.001$ \\
\hline Systolic blood pressure & $125.93 \pm 23.34$ & $126.30 \pm 21.41$ & $125.36 \pm 26.09$ & 0.658 \\
\hline LVEF, \% & $51.16 \pm 13.60$ & $52.21 \pm 14.02$ & $49.54 \pm 12.79$ & 0.030 \\
\hline LVEF <40\%, n (\%) & $110(21.5)$ & $67(21.5)$ & $43(21.5)$ & 0.991 \\
\hline Mehran Score & $10.79 \pm 4.20$ & $9.70 \pm 3.53$ & $12.48 \pm 4.58$ & $<0.001$ \\
\hline Weight, kg & $63.43 \pm 10.71$ & $65.27 \pm 10.53$ & $60.59 \pm 10.38$ & $<0.001$ \\
\hline \multicolumn{5}{|l|}{ Medical history, $n(\%)$} \\
\hline Diabetes mellitus & $66(30.1)$ & $93(27.8)$ & $73(33.6)$ & 0.147 \\
\hline Smoker & $204(37.0)$ & $122(36.5)$ & $82(37.8)$ & 0.765 \\
\hline Hypertension & $334(60.6)$ & $196(58.7)$ & $138(63.6)$ & 0.249 \\
\hline Hyperlipidemia & $73(13.2)$ & $49(14.7)$ & $24(11.1)$ & 0.222 \\
\hline Prior MI & $55(10.0)$ & $27(8.1)$ & $28(12.9)$ & 0.065 \\
\hline History of CABG & $6(1.1)$ & $2(0.6)$ & $4(1.8)$ & 0.169 \\
\hline \multicolumn{5}{|l|}{ Laboratory measurements } \\
\hline $\mathrm{LDL}-\mathrm{C}, \mathrm{mmol} / \mathrm{L}$ & $2.82 \pm 0.97$ & $2.75 \pm 0.96$ & $2.93 \pm 0.98$ & 0.118 \\
\hline $\mathrm{HDL}-\mathrm{C}, \mathrm{mmol} / \mathrm{L}$ & $0.88 \pm 0.30$ & $2.93 \pm 0.98$ & $0.90 \pm 0.34$ & 0.489 \\
\hline Total cholesterol, mmol/L & $4.56 \pm 1.19$ & $4.52 \pm 1.20$ & $4.52 \pm 1.20$ & 0.480 \\
\hline $\log \mathrm{BNP}$ & $7.23 \pm 1.65$ & $6.99 \pm 1.61$ & $7.66 \pm 1.62$ & $<0.001$ \\
\hline $\mathrm{HbA1c}, \%$ & $6.76 \pm 1.52$ & $6.78 \pm 1.58$ & $6.72 \pm 1.43$ & 0.699 \\
\hline hs-CRP, mg/L & $6.76 \pm 1.52$ & $24.72 \pm 37.11$ & $28.95 \pm 38.98$ & 0.347 \\
\hline Anemia, $n(\%)$ & $224(41.1)$ & $118(35.8)$ & $106(49.3)$ & 0.002 \\
\hline Hematocrit, \% & $0.38 \pm 0.06$ & $0.38 \pm 0.05$ & $0.37 \pm 0.06$ & 0.024 \\
\hline \multicolumn{5}{|l|}{ Medication, $n(\%)$} \\
\hline ACEI/ARB & $463(84.0)$ & $289(86.5)$ & $174(80.2)$ & 0.047 \\
\hline$\beta$-blocker & $414(75.3)$ & $463(84.0)$ & $154(71.0)$ & 0.059 \\
\hline $\mathrm{CCB}$ & $71(13.0)$ & $35(10.5)$ & $35(10.5)$ & 0.035 \\
\hline Diuretics & $270(49.0)$ & $145(43.4)$ & $125(57.6)$ & 0.001 \\
\hline \multicolumn{5}{|l|}{ Procedure } \\
\hline Emergency PCI, $n(\%)$ & $171(31.0)$ & $86(25.7)$ & $85(39.2)$ & $<0.001$ \\
\hline Coronary lesions & $2.25 \pm 1.07$ & $2.13 \pm 1.07$ & $2.45 \pm 1.04$ & 0.002 \\
\hline Coronary stents & $1.57 \pm 1.20$ & $2.45 \pm 1.04$ & $2.45 \pm 1.04$ & 0.199 \\
\hline Total length of stent (mm) & $40.00 \pm 32.81$ & $37.44 \pm 31.01$ & $44.39 \pm 35.36$ & 0.030 \\
\hline Procedure duration (min) & $79.37 \pm 43.35$ & $76.69 \pm 41.46$ & $83.52 \pm 45.91$ & 0.073 \\
\hline
\end{tabular}


Contrast volume $(\mathrm{mL})$

Contrast volume $>200 \mathrm{~mL}$

$\mathrm{HV} / \mathrm{W}, \mathrm{mL} / \mathrm{kg}$

$\mathrm{HV}, \mathrm{mL}$

$$
\begin{gathered}
128.40 \pm 62.39 \\
75(13.6) \\
15.26 \pm 9.55
\end{gathered}
$$

$938.75 \pm 563.10$

$$
\begin{gathered}
127.07 \pm 61.56 \\
43(12.9) \\
9.61 \pm 2.65
\end{gathered}
$$$$
619.58 \pm 183.42
$$

$\begin{array}{cc}130.46 \pm 63.74 & 0.533 \\ 32(14.7) & 0.531 \\ 23.95 \pm 9.80 & <0.001 \\ 1430.02 \pm 596.27 & <0.001\end{array}$

Abbreviations: $\mathrm{CrCl}$, creatinine clearance; $\mathrm{LVEF}$, left ventricular ejection fraction; MI, myocardial infarction; CABG, coronary artery bypass grafting; LDL-C, low-density lipoprotein-cholesterol; HDL-C, high-density lipoprotein-cholesterol;

\begin{tabular}{|c|c|c|c|c|}
\hline \multirow[b]{2}{*}{ Characteristics } & \multirow[b]{2}{*}{$\begin{array}{c}\text { Total } \\
(n=551)\end{array}$} & \multicolumn{3}{|c|}{ HV/W } \\
\hline & & $\begin{array}{c}\mathrm{HV} / \mathrm{W} \leq 15 \mathrm{~mL} / \mathrm{kg} \\
(n=334)\end{array}$ & $\begin{array}{c}\mathrm{HV} / \mathrm{W}>15 \mathrm{~mL} / \mathrm{kg} \\
(n=217)\end{array}$ & P-value \\
\hline \multicolumn{5}{|l|}{ In-hospital outcomes } \\
\hline CI-AKI, $n(\%)$ & $92(17.0)$ & $36(11.0)$ & $56(26.3)$ & $<0.001$ \\
\hline WHF, $n(\%)$ & $55(10.0)$ & $19(5.7)$ & $36(16.7)$ & $<0.001$ \\
\hline \multicolumn{5}{|l|}{ 2-year clinical outcomes } \\
\hline MACE, $n(\%)$ & $151(34.2)$ & $71(26.5)$ & $80(46.0)$ & $<0.001$ \\
\hline Mortality, $n(\%)$ & $66(15.1)$ & $24(9.1)$ & $42(24.6)$ & $<0.001$ \\
\hline Dialysis, $n(\%)$ & $17(4.0)$ & $5(1.9)$ & $12(7.5)$ & 0.004 \\
\hline Re-hospitalization, $n(\%)$ & $77(18.8)$ & $45(17.3)$ & $32(21.5)$ & 0.299 \\
\hline TVR, $n(\%)$ & $6(1.5)$ & $1(0.4)$ & $5(3.3)$ & 0.017 \\
\hline Stroke, $n(\%)$ & $7(1.7)$ & $1(0.4)$ & $6(3.9)$ & 0.007 \\
\hline \multicolumn{5}{|l|}{ 3-year clinical outcomes } \\
\hline MACE, $n(\%)$ & $176(39.8)$ & $86(32.1)$ & $90(51.7)$ & $<0.001$ \\
\hline Mortality, $n(\%)$ & $72(16.5)$ & $29(10.9)$ & $43(25.1)$ & $<0.001$ \\
\hline Dialysis, $n(\%)$ & $17(4.0)$ & $5(1.9)$ & $12(7.5)$ & 0.004 \\
\hline Re-hospitalization, $n(\%)$ & $97(23.7)$ & $55(21.2)$ & $42(28.2)$ & 0.108 \\
\hline TVR, $n(\%)$ & $7(1.7)$ & $2(0.8)$ & $5(3.3)$ & 0.054 \\
\hline Stroke, $n(\%)$ & $7(1.7)$ & $1(0.4)$ & $6(3.9)$ & 0.007 \\
\hline
\end{tabular}
BNP, B-type natriuretic peptide; HbA1c, glycated hemoglobin; hs-CRP, high-sensitivity C-reactive protein; ACEI/ARB, angiotensin-converting enzyme inhibitor/angiotensin receptor blocker; $\mathrm{CCB}$, calcium channel blocker; PCI, percutaneous coronary intervention; HV, hydration volume.

Table 2: In-hospital and clinical outcomes during follow-up according to the hydration volume-to-body weight ratio $(\mathrm{HV} / \mathrm{W} \leq 15$ and $\mathrm{HV} / \mathrm{W}>15 \mathrm{~mL} / \mathrm{kg})$

Abbreviations: CI-AKI, contrast-induced acute kidney injury; WHF, worsening heart failure; MACE, major adverse clinical events; AMI, acute myocardial infarction; TVR, target vessel revascularization.

and WHF were significantly associated with an increased risk of long-term mortality after CAG.

Current studies have shown a lack of consistency regarding the optimal hydration volume and duration for preventing CI-AKI, especially in patients with CHF patients [13]. The 2010 European Guidelines recommend hydration at a rate of $0.5 \mathrm{~mL} / \mathrm{kg} / \mathrm{h}$ for 12 hours before and 24 hours afterward for patients with CHF and chronic kidney disease; however, this recommendation was not supported with clinical evidence [5]. The 2014 ESC guidelines recommend a reduction of the hydration volume from the initial dose of $250 \mathrm{~mL}$, generally recommended for patients, to $150 \mathrm{~mL}$ (over 30 minutes) in patients with kidney disease and left ventricular dysfunction (Class IIb) [4]. Marenzi et al. recommended hydration with normal saline $(0.9 \%)$ at a rate of $0.5 \mathrm{ml} / \mathrm{kg} / \mathrm{h}$ for 12 hours among patients with overt heart failure or left ventricular dysfunction (ejection fraction $<40 \%$ ) undergoing primary PCI [7]. Our data in the present study showed that a higher hydration volume increased the risk of CI-AKI and WHF. A hydration volume-to-weight ratio less than $15 \mathrm{~mL} / \mathrm{kg}$, equal to hydration for 30 hours at $0.5 \mathrm{~mL} / \mathrm{kg} / \mathrm{h}$, seemed associated with a reduced risk of CI-AKI or WHF following CAG or PCI among patients with advanced CHF. 
Table 3: Univariate analyses and multivariate associations between contrast-induced acute kidney injury and a hydration volume-to-body weight ratio (HV/W > $15 \mathrm{vs} . \mathrm{HV} / \mathrm{W} \leq 15 \mathrm{~mL} / \mathrm{kg})$

\begin{tabular}{|c|c|c|c|c|c|c|}
\hline \multirow{2}{*}{ Risk factors } & \multicolumn{3}{|c|}{ Univariate logistic regression } & \multicolumn{3}{|c|}{ Multivariate logistic regression } \\
\hline & OR & $95 \% \mathrm{CI}$ & $P$-value & OR & $95 \% \mathrm{CI}$ & $P$-value \\
\hline $\mathrm{HV} / \mathrm{W}>15 \mathrm{~mL} / \mathrm{kg}$ & 2.88 & $1.82-4.57$ & $<0.001$ & 2.33 & $1.26-4.31$ & 0.007 \\
\hline Age & 1.05 & $1.03-1.08$ & $<0.001$ & 1.04 & $1.01-1.08$ & 0.023 \\
\hline $\mathrm{CrCl}$ & 0.98 & $0.97-0.99$ & $<0.001$ & 1.01 & $0.99-1.02$ & 0.227 \\
\hline Diabetes mellitus & 1.15 & $0.71-1.85$ & 0.578 & 1.18 & $0.63-2.21$ & 0.602 \\
\hline Anemia & 1.53 & $0.97-2.40$ & 0.067 & 1.49 & $0.78-2.82$ & 0.225 \\
\hline Use of IABP & 6.71 & $3.90-11.55$ & $<0.001$ & 4.83 & $2.31-10.12$ & $<0.001$ \\
\hline Use of diuretic & 2.04 & $1.28-3.24$ & 0.003 & 1.48 & $0.80-2.74$ & 0.210 \\
\hline Coronary lesion & 1.40 & $1.09-1.80$ & 0.009 & 1.31 & $0.97-1.76$ & 0.075 \\
\hline Emergency PCI & 2.92 & $1.84-4.61$ & $<0.001$ & 3.55 & $1.80-7.01$ & $<0.001$ \\
\hline Hypertension & 3.51 & $1.72-7.16$ & 0.001 & 0.37 & $0.08-1.73$ & 0.205 \\
\hline
\end{tabular}

Abbreviations: OR, odds ratio; $\mathrm{CI}$, confidence interval; $\mathrm{CrCl}$, creatinine clearance; IABP, intra-aortic balloon pump; PCI, percutaneous coronary intervention.

Table 4: Univariate analyses and multivariate associations between worsening heart failure and hydration volume-tobody weight ratio $(\mathrm{HV} / \mathrm{W}>15 \mathrm{vs} . \mathrm{HV} / \mathrm{W} \leq 15 \mathrm{~mL} / \mathrm{kg})$

\begin{tabular}{|c|c|c|c|c|c|c|}
\hline \multirow{2}{*}{ Risk factors } & \multicolumn{3}{|c|}{ Univariate logistic regression } & \multicolumn{3}{|c|}{ Multivariate logistic regression } \\
\hline & OR & $95 \% \mathrm{CI}$ & $P$-value & OR & $95 \%$ CI & $P$-value \\
\hline $\mathrm{HV} / \mathrm{W}>15 \mathrm{~mL} / \mathrm{kg}$ & 3.26 & $1.82-5.85$ & $<0.001$ & 2.13 & $1.14-3.99$ & 0.018 \\
\hline Age & 1.03 & $1.01-1.06$ & 0.017 & 1.02 & $0.99-1.05$ & 0.265 \\
\hline Anemia & 1.38 & $0.79-2.43$ & 0.261 & 1.18 & $0.64-2.20$ & 0.594 \\
\hline Use of IABP & 4.14 & $2.20-7.80$ & $<0.001$ & 2.45 & $1.24-4.84$ & 0.010 \\
\hline Use of diuretic & 3.81 & $2.00-7.28$ & $<0.001$ & 2.82 & $1.43-5.57$ & 0.003 \\
\hline Emergency PCI & 4.23 & $2.37-7.55$ & $<0.001$ & 3.38 & $1.81-6.31$ & $<0.001$ \\
\hline
\end{tabular}

Abbreviations: OR, odds ratio; CI, confidence interval; IABP, intra-aortic balloon pump; PCI, percutaneous coronary intervention.
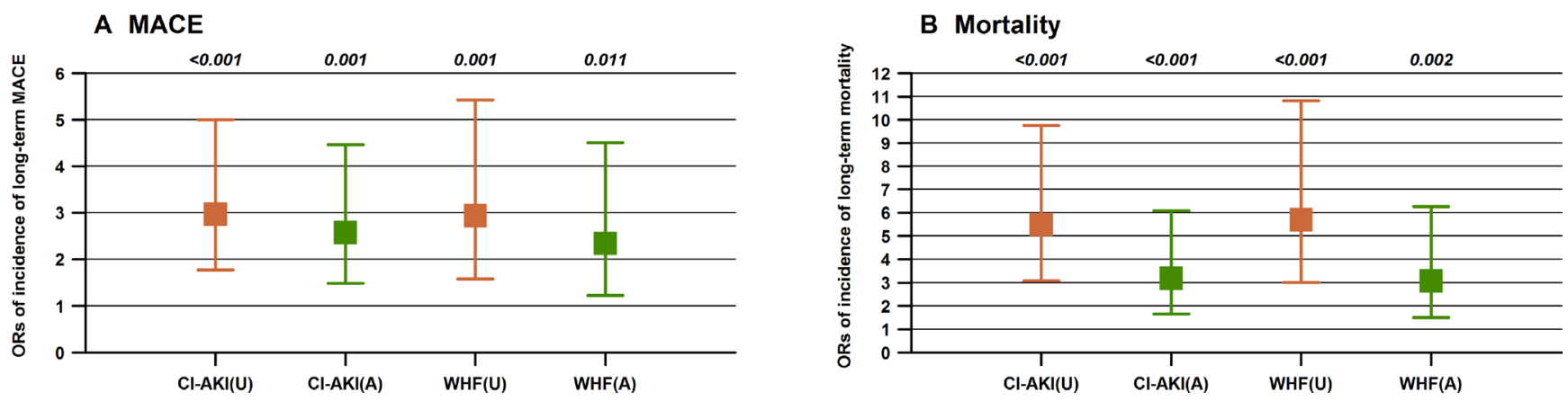

Figure 3: Unadjusted (U) and adjusted (A) odds ratios for long-term mortality (Panel B) and MACE (Panel A) among patients with CI-AKI or WHF. 
Iatrogenic hyper-hydration may lead to fluid overload, which results in renal tissue edema, impaired oxygen and metabolite diffusion, distorted renal tissue architecture, and obstruction of capillary blood flow and lymphatic drainage; contributing to the progression of CI-AKI $[8,14]$. Fluid overload may also worsen intra-abdominal hypertension, particularly in critically ill trauma or burn patients, leading to further reductions in renal blood flow, venous outflow, renal perfusion pressure, and urine output. These outcomes are, in turn, strongly associated with the development of CI-AKI [15].

Multiple data consistently demonstrate that fluid overload plays a central role in the pathogenesis of WHF and patient hospitalization. Fluid overload and increased ventricular volumes, therefore, foster left ventricular remodeling and mitral regurgitation both directly, through myocardial stretch and indirectly, through the activation of the renin-angiotensinaldosterone, adrenergic, and cytokine systems [16, 17]. Fluid overload and increased intraventricular pressure also cause coronary hypoperfusion and subendocardial ischemia, which may further impair cardiac function [18]. A recent study showed that central venous pressure (CVP)-guided hydration can safely and effectively reduce the risk of CI-AKI in patients with chronic kidney disease and CHF, without increasing the incidence of acute heart failure [19]. However, CVP measurement is invasive and its use as a routine procedure in clinical practice is infeasible.

In the present study, we found that CI-AKI was significantly associated with long-term mortality, which is in general agreement with the results of our previous study $[20,21]$. A meta-analysis by James et al. investigated the association between CI-AKI after CAG and adverse clinical outcomes [22]. Of the 34 included studies examining mortality, 33 reported significantly increased mortality rates in patients who developed CI-AKI after CAG. The pooled adjusted risk ratio for mortality and cardiovascular events was 2.39 and 1.98, respectively, after adjustment for confounders in 23 studies.

WHF was also significantly associated with longterm mortality in the present study. Similarly, a previous study found that patients who experienced WHF had markedly worse clinical outcomes at 30 and 180 days
[3]. By 180 days, $41.5 \%$ of patients with WHF had died compared with $11.3 \%$ of patients without WHF. In another study assessing patients who were admitted to a hospital for acute heart failure, WHF occurred in $27 \%$ patients and was associated with prolonged hospitalization and higher readmission and death rates [23]. However, few studies have focused on WHF and prognosis in patients with advanced CHF undergoing CAG. Our study provides strong evidence over a long follow-up period (2.48 years) that in patients with advanced CHF undergoing CAG, WHF also significantly increases the risk of long-term MACE.

Recently, the AMACING trial investigated the effect of hydration on the risk of contrast-induced nephropathy (CIN) and cost among patients receiving contrast exposure, and showed that no-hydration was noninferior and cost-saving for preventing contrast-induced nephropathy compared with intravenous hydration recommended by current clinical practice guidelines $[4,8,24,25]$. Although no data of baseline heart function (history of heart failure, left ventricular ejection fraction, heart function classification, or other biomarkers) were available in the AMACING study, the guidelines hydration protocol increased the risk of post-hydration symptomatic heart failure ( $4 \%$ vs $0 \%$, suggesting the importance of safe hydration for preventing CI-AKI, especially among patients with pre-existing advanced heart failure.

\section{Study limitations}

The present study has several limitations. First, our study was a single-center prospective observational study with a limited sample size. The results from this hypothesis-generating study need further assessment in a randomized controlled trial. Second, variation in the measurement times may have led to the missing of postprocedural peak levels of creatinine. Thirdly, there may have been some bias in the final hydration volume, as cardiologists may administer higher hydration volumes for patients with more baseline risk factors for CI-AKI and WHF. This, in turn, may have confounded the results regarding the effect of hydration volume on the risk of CIAKI and WHF, despite the adjustment for confounders. Fourthly, although we previously set up the same
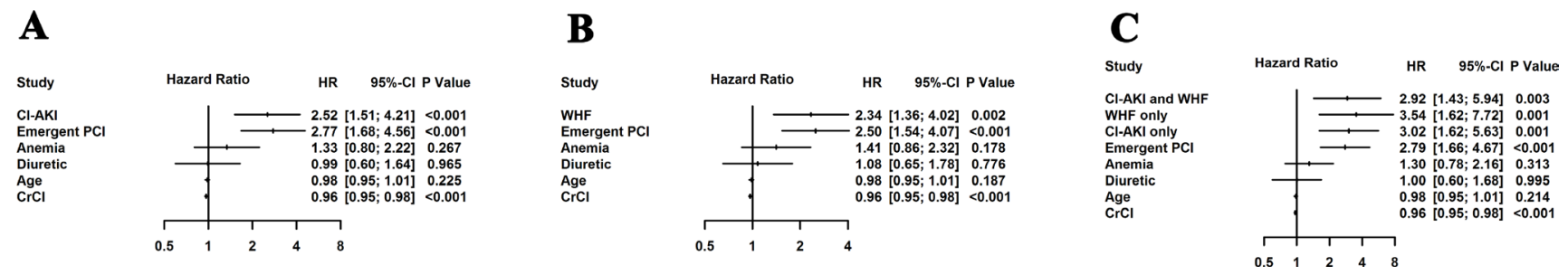

Figure 4: Adjusted hazard ratios of Cox analysis for mortality of CI-AKI vs. No CI-AKI (A), WHF vs. No WHF (B), and CI-AKI and WHF combined groups (C). CI-AKI, contrast-induced acute kidney injury; WHF, worsening heart failure. 
hydration speed for those patients, physicians or nurses involved in the management of some patients may have adjusted the final hydration speed, which was also an unadjusted-for confounder. These possible variations of the hydration protocol owing to the treating physician and nurses may have significantly affected the study results. Finally, data was lacking regarding oral water intake and we were unable to investigate whether patients with low hydration volumes might have drunk more water (higher oral hydration volume) and had reached the same or similar hydration volumes as those treated with higher intravenous hydration volumes.

\section{METHODS}

\section{Subjects}

In this prospective observational study, we enrolled patients who were candidates for CAG or PCI between January 2010 and October 2012, according to the institutional protocol. As per our sub-study in a previous publication [12], we included patients aged $\geq 18$ years who had advanced CHF (NYHA class $>2$ ) or a history of pulmonary edema $[2,26]$. As per the updated European Society of Urogenital Radiology Contrast Media Safety Committee guidelines [27], the exclusion criteria included pregnancy, lactation, intravascular administration of contrast medium within 7 days before or 3 days after the procedure), non-use of low-osmolarity contrast agents, cardiovascular surgery or endovascular repair, end-stage renal disease or renal replacement, missing pre- or postoperative creatinine values, malignancy, nonuse of isotonic saline for hydration, and patients without advanced CHF (Supplementary Figure 1).

Follow-up events were carefully monitored and recorded by trained nurses through office visits and telephone interviews at 1, 6, 12, 24, 36, and 48 months after CAG. The mean follow-up time was $2.62 \pm 0.9$ years (median, 2.48; interquartile range [IQR], 1.89-3.45 years). The investigation complied with the principles outlined in the Declaration of Helsinki and was approved by the Ethics Committee of the Guangdong General Hospital. All patients gave their written informed consent.

\section{Coronary angiography}

Cardiac catheterization was performed according to standard clinical practice [9]. All patients received non-ionic, low-osmolarity contrast agents. Patients were treated based on recent guidelines [27]. All patients received a continuous intravenous infusion of isotonic saline at a rate of $0.5 \mathrm{~mL} / \mathrm{kg} / \mathrm{h}$ for at least 2 to 12 hours before the procedure and continued to receive it 6 to 24 hours afterward. Serum creatinine concentrations were also measured in accordance with our clinical protocol
[9] in all patients on admission to the hospital and on day 1,2, and 3 after the procedure. Creatinine clearance was calculated using the Cockcroft-Gault formula [28], and hydration volume/weight $(\mathrm{HV} / \mathrm{W}, \mathrm{mL} / \mathrm{kg})$ ratios were calculated.

\section{Endpoints and definitions}

The primary endpoint was the first occurrence of CI-AKI and WHF, and the secondary endpoint was the first occurrence of any MACE during follow-up. CI-AKI was defined as an increase in serum creatinine of $\geq 0.3 \mathrm{mg} / \mathrm{dL}$ or $\geq 50 \%$ from baseline within 48 hours of contrast exposure [29]. WHF was defined as the presence of at least one sign, symptom, or radiologic indication of new, persistent, or worsening acute heart failure requiring the addition of new intravenous therapy (inotrope or vasodilator) or mechanical support during a patient's index hospitalization targeted specifically at heart failure symptoms [3]. MACE was defined as mortality, re-non-fatal acute myocardial infarction, target vessel revascularization, CI-AKI requiring renal replacement therapy, stroke, and re-hospitalization after the index hospitalization.

\section{Statistical analysis}

For continuous variables, two independent sample $t$-tests were performed for normally distributed data (presented as mean \pm standard deviation), and the Wilcoxon rank-sum test was used for non-normal distributions (presented as median and IQR). Pearson's chi-square test or Fisher's exact test were used as appropriate for categorical data, which are expressed as percentages. The Cochran-Armitage test was performed to investigate the association between $\mathrm{HV} / \mathrm{W}$ and the incidence of CI-AKI and WHF. ROC curves were used to identify the optimal sensitivity for the observed range of $\mathrm{HV} / \mathrm{W}$ for CI-AKI.

After balancing overfitting and the good control of unbalanced factors, we used factors with $P$-values $<$ 0.05 at baseline analysis along with clinically important factors for the multivariate logistic analysis to ascertain the ability of HV/W ( $>15 \mathrm{~mL} / \mathrm{kg}$ vs. $\leq 15 \mathrm{~mL} / \mathrm{kg})$ to predict CI-AKI and WHF. Univariate analyses of mortality were performed using the log-rank test, and multivariate Cox regression analyses adjusting for the use of an intraaortic balloon pump, anemia, diabetes mellitus, emergency PCI, age ( $>75$ years), and for other factors were also performed.

The data were analyzed on an available case basis, and missing data were not included. All data analyses were performed using SAS version 9.4 (SAS Institute, Cary, NC, USA) and R software (version 3.1.2, R Core Team, Vienna, Austria) [30]. Two-sided $P$-values $<0.05$ were considered statistically significant. 


\section{CONCLUSIONS}

Our data showed that higher hydration volumes were associated with a significantly increased risk of CI-AKI and WHF after CAG in high-risk patients with advanced CHF. The relatively safe hydration volume for patients with advanced CHF might be as low as $15 \mathrm{~mL} / \mathrm{kg}$. Moreover, CI-AKI and WHF were associated with a significantly increased risk of long-term mortality. The potential renal and heart safety benefits of a personalized control of hydration volume in patients with advanced CHF need to be investigated in further large-scale multicenter randomized controlled trials.

\section{Abbreviations}

CAG: coronary angiography; CHF: congestive heart failure; CI: confidence interval; CI-AKI: contrast-induced acute kidney injury; CVP: central venous pressure; HR: hazard ratio; HV/W: hydration volume-to-weight ratio; IQR: interquartile range; MACE: major adverse clinical events; NYHA: New York Heart Association; OR: odds ratio; PCI: percutaneous coronary intervention; ROC: receiver operating characteristic; WHF: worsening heart failure.

\section{Author contributions}

S.C., Y.L., W.B., D.W., W.K., N.T., J.C. and P.C. conception or design of the work, Y.L., C.D., S.C. and P.C. acquisition, analysis or interpretation of data. Y.W., N.T., J.C., P.C. and Y.Z. drafting the work or revising it critically for important intellectual content. S.C., Y.L., W.B., D.W., Y.W., C.D., P.C., Y.X., J.C., K.W. and N.T. final approval of the version published. All authors agreed to be accountable for all aspects of the work in ensuring that questions related to the accuracy or integrity of any part of the work are appropriately investigated and resolved.

\section{CONFLICTS OF INTEREST}

The authors have nothing to disclose.

\section{FUNDING}

This work was supported by the Guangdong Provincial Cardiovascular Clinical Medicine Research Fund (grant number 2009X41); Science and Technology Planning Project of Guangdong Province (PRECOMIN study; study grant number 2008A030201002); and the Guangdong Cardiovascular Institute. The funders had no role in the study design, data collection, and analysis, decision to publish, or preparation of the manuscript. The study was not funded by any industry sponsors.

\section{REFERENCES}

1. McCullough PA. Contrast-induced acute kidney injury. J Am Coll Cardiol. 2008; 51:1419-28. https://doi. org/10.1016/j.jacc.2007.12.035.

2. Mehran R, Aymong ED, Nikolsky E, Lasic Z, Iakovou I, Fahy M, Mintz GS, Lansky AJ, Moses JW, Stone GW, Leon MB, Dangas G. A simple risk score for prediction of contrast-induced nephropathy after percutaneous coronary intervention: development and initial validation. J Am Coll Cardiol. 2004; 44:1393-99.

3. Kelly JP, Mentz RJ, Hasselblad V, Ezekowitz JA, Armstrong PW, Zannad F, Felker GM, Califf RM, O'Connor CM, Hernandez AF. Worsening heart failure during hospitalization for acute heart failure: Insights from the Acute Study of Clinical Effectiveness of Nesiritide in Decompensated Heart Failure (ASCEND-HF). Am Heart J. 2015; 170:298-305. https://doi.org/10.1016/j.ahj.2015.04.007.

4. Windecker S, Kolh P, Alfonso F, Collet JP, Cremer J, Falk V, Filippatos G, Hamm C, Head SJ, Jüni P, Kappetein AP, Kastrati A, Knuuti J, et al, and Authors/ Task Force members. 2014 ESC/EACTS Guidelines on myocardial revascularization: The Task Force on Myocardial Revascularization of the European Society of Cardiology (ESC) and the European Association for CardioThoracic Surgery (EACTS)Developed with the special contribution of the European Association of Percutaneous Cardiovascular Interventions (EAPCI). Eur Heart J. 2014; 35:2541-619. https://doi.org/10.1093/eurheartj/ehu278.

5. Wijns W, Kolh P, Danchin N, Di Mario C, Falk V, Folliguet T, Garg S, Huber K, James S, Knuuti J, LopezSendon J, Marco J, Menicanti L, et al, and Task Force on Myocardial Revascularization of the European Society of Cardiology (ESC) and the European Association for CardioThoracic Surgery (EACTS), and European Association for Percutaneous Cardiovascular Interventions (EAPCI). Guidelines on myocardial revascularization. Eur Heart J. 2010; 31:2501-55. https://doi.org/10.1093/eurheartj/ehq277.

6. Di Somma S, Gori CS, Grandi T, Risicato MG, Salvatori E. Fluid assessment and management in the emergency department. Contrib Nephrol. 2010; 164:227-36. https:// doi.org/10.1159/000313734.

7. Wang N, Jiang L, Zhu B, Wen Y, Xi XM, and Beijing Acute Kidney Injury Trial (BAKIT) Workgroup. Fluid Balance and Mortality in Critically Ill Patients with Acute Kidney Injury: A Multi-center Prospective Epidemiological study. Crit Care. 2015; 19:371. https://doi.org/10.1186/ s13054-015-1085-4.

8. Zhang L, Chen Z, Diao Y, Yang Y, Fu P. Associations of fluid overload with mortality and kidney recovery in patients with acute kidney injury: A systematic review and meta-analysis. J Crit Care. 2015; 30:860.e7-13. https://doi. org/10.1016/j.jcrc.2015.03.025.

9. Samoni S, Vigo V, Reséndiz LI, Villa G, De Rosa S, Nalesso F, Ferrari F, Meola M, Brendolan A, Malacarne P, Forfori F, 
Bonato R, Donadio C, Ronco C. Impact of hyperhydration on the mortality risk in critically ill patients admitted in intensive care units: comparison between bioelectrical impedance vector analysis and cumulative fluid balance recording. Crit Care. 2016; 20:95. https://doi.org/10.1186/ s13054-016-1269-6.

10. Marenzi G, Lauri G, Assanelli E, Campodonico J, De Metrio M, Marana I, Grazi M, Veglia F, Bartorelli AL. Contrast-induced nephropathy in patients undergoing primary angioplasty for acute myocardial infarction. J Am Coll Cardiol. 2004; 44:1780-85. https://doi.org/10.1016/j. jacc.2004.07.043.

11. O'Gara PT, Kushner FG, Ascheim DD, Casey DE Jr, Chung MK, de Lemos JA, Ettinger SM, Fang JC, Fesmire FM, Franklin BA, Granger CB, Krumholz HM, Linderbaum JA, et al, and American College of Emergency Physicians, and Society for Cardiovascular Angiography and Interventions. 2013 ACCF/AHA guideline for the management of ST-elevation myocardial infarction: a report of the American College of Cardiology Foundation/American Heart Association Task Force on Practice Guidelines. J Am Coll Cardiol. 2013; 61:e78-140. https://doi.org/10.1016/j. jacc.2012.11.019.

12. Liu Y, Chen JY, Tan N, Zhou YL, Yu DQ, Chen ZJ, He YT, Liu YH, Luo JF, Huang WH, Li G, He PC, Yang JQ, et al. Safe limits of contrast vary with hydration volume for prevention of contrast-induced nephropathy after coronary angiography among patients with a relatively low risk of contrast-induced nephropathy. Circ Cardiovasc Interv. 2015; 8:e01859. https://doi.org/10.1161/ CIRCINTERVENTIONS.114.001859.

13. Navaneethan SD, Singh S, Appasamy S, Wing RE, Sehgal AR. Sodium bicarbonate therapy for prevention of contrastinduced nephropathy: a systematic review and metaanalysis. Am J Kidney Dis. 2009; 53:617-27. https://doi. org/10.1053/j.ajkd.2008.08.033.

14. Prowle JR, Echeverri JE, Ligabo EV, Ronco C, Bellomo R. Fluid balance and acute kidney injury. Nat Rev Nephrol. 2010; 6:107-15. https://doi.org/10.1038/nrneph.2009.213.

15. Shear W, Rosner MH. Acute kidney dysfunction secondary to the abdominal compartment syndrome. J Nephrol. 2006; 19:556-65.

16. Mann DL, Bristow MR. Mechanisms and models in heart failure: the biomechanical model and beyond. Circulation. 2005; 111:2837-49. https://doi.org/10.1161/ CIRCULATIONAHA.104.500546.

17. Metra M, Dei Cas L, Bristow MR. The pathophysiology of acute heart failure - it is a lot about fluid accumulation. Am Heart J. 2008; 155:1-5. https://doi.org/10.1016/j. ahj.2007.10.011.

18. Agostoni PG, Marenzi GC, Pepi M, Doria E, Salvioni A, Perego G, Lauri G, Giraldi F, Grazi S, Guazzi MD. Isolated ultrafiltration in moderate congestive heart failure. J Am Coll Cardiol. 1993; 21:424-31. https://doi. org/10.1016/0735-1097(93)90685-T.
19. Qian G, Fu Z, Guo J, Cao F, Chen Y. Prevention of ContrastInduced Nephropathy by Central Venous Pressure-Guided Fluid Administration in Chronic Kidney Disease and Congestive Heart Failure Patients. JACC Cardiovasc Interv. 2016; 9:89-96. https://doi.org/10.1016/j.jcin.2015.09.026.

20. Liu Y, Liu Y, Li H, Zhou Y, Guo W, Duan C, Chen S, Chen P, Tan N, Chen J. Percutaneous coronary intervention for chronic total occlusion improved prognosis in patients with renal insufficiency at high risk of contrast-induced nephropathy. Sci Rep. 2016; 6:21426. https://doi. org/10.1038/srep21426.

21. Pyxaras SA, Zhang Y, Wolf A, Schmitz T, Naber CK. Effect of Varying Definitions of Contrast-Induced Acute Kidney Injury and Left Ventricular Ejection Fraction on One-Year Mortality in Patients Having Transcatheter Aortic Valve Implantation. Am J Cardiol. 2015; 116:426-30. https://doi. org/10.1016/j.amjcard.2015.04.056.

22. James MT, Samuel SM, Manning MA, Tonelli M, Ghali WA, Faris P, Knudtson ML, Pannu N, Hemmelgarn BR. Contrastinduced acute kidney injury and risk of adverse clinical outcomes after coronary angiography: a systematic review and meta-analysis. Circ Cardiovasc Interv. 2013; 6:37-43. https://doi.org/10.1161/CIRCINTERVENTIONS.112.974493.

23. Cotter G, Metra M, Davison BA, Senger S, Bourge RC, Cleland JG, Jondeau G, Krum H, O’Connor CM, Parker JD, Torre-Amione G, van Veldhuisen DJ, Milo O, et al, and VERITAS Investigators. Worsening heart failure, a critical event during hospital admission for acute heart failure: results from the VERITAS study. Eur J Heart Fail. 2014; 16:1362-71. https://doi.org/10.1002/ejhf.186.

24. Stacul F, van der Molen AJ, Reimer P, Webb JA, Thomsen HS, Morcos SK, Almén T, Aspelin P, Bellin MF, Clement O, Heinz-Peer G, and Contrast Media Safety Committee of European Society of Urogenital Radiology (ESUR). Contrast induced nephropathy: updated ESUR Contrast Media Safety Committee guidelines. Eur Radiol. 2011; 21:2527-41. https://doi.org/10.1007/s00330-011-2225-0.

25. Nijssen EC, Rennenberg RJ, Nelemans PJ, Essers BA, Janssen MM, Vermeeren MA, Ommen VV, Wildberger JE. Prophylactic hydration to protect renal function from intravascular iodinated contrast material in patients at high risk of contrast-induced nephropathy (AMACING): a prospective, randomised, phase 3, controlled, open-label, non-inferiority trial. Lancet. 2017; 389:1312-22. https://doi. org/10.1016/S0140-6736(17)30057-0.

26. Caixeta A, Nikolsky E, Mehran R. Prevention and treatment of contrast-associated nephropathy in interventional cardiology. Curr Cardiol Rep. 2009; 11:377-83. https://doi. org/10.1007/s11886-009-0052-6.

27. Wright RS, Anderson JL, Adams CD, Bridges CR, Casey DE Jr, Ettinger SM, Fesmire FM, Ganiats TG, Jneid H, Lincoff AM, Peterson ED, Philippides GJ, Theroux P, et al. 2011 ACCF/AHA focused update of the Guidelines for the Management of Patients with Unstable Angina/NonST-Elevation Myocardial Infarction (updating the 2007 
guideline): a report of the American College of Cardiology Foundation/American Heart Association Task Force on Practice Guidelines developed in collaboration with the American College of Emergency Physicians, Society for Cardiovascular Angiography and Interventions, and Society of Thoracic Surgeons. J Am Coll Cardiol. 2011; 57:1920 59. https://doi.org/10.1016/j.jacc.2011.02.009.

28. Xun L, Cheng W, Hua T, Chenggang S, Zhujiang C, Zengchun Y, Tanqi L. Assessing glomerular filtration rate (GFR) in elderly Chinese patients with chronic kidney disease (CKD): a comparison of various predictive equations. Arch Gerontol Geriatr. 2010; 51:13-20. https:// doi.org/10.1016/j.archger.2009.06.005.
29. Moriyama N, Ishihara M, Noguchi T, Nakanishi M, Arakawa T, Asaumi Y, Kumasaka L, Kanaya T, Miyagi T, Nagai T, Yamane T, Fujino M, Honda S, et al. Admission hyperglycemia is an independent predictor of acute kidney injury in patients with acute myocardial infarction. Circ J. 2014; 78:1475-80. https://doi.org/10.1253/circj.CJ-14-0117.

30. R Core Team. R: A Language and Environment for Statistical Computing. R Foundation for Statistical Computing, Vienna, Austria. 2015 Oct 21. http://www.Rproject.org/. 